\title{
Internet Use and Its Addiction Among Medical Students in Hyderabad, Pakistan
}

\author{
Tariq Feroz Memon ${ }^{1}$, Ghulam Hussain Baloch ${ }^{2}$, Muhammad Talha Khan ${ }^{3}$, Ferrukh Zehravi ${ }^{4}$, Munawar \\ Hussain Soomro ${ }^{5}$, Jehanzaib Motlani ${ }^{6}$ \\ ${ }^{1}$ Assistant Professor, Department of Community Medicine, Liaquat University of Medical \& Health Sciences, Jamshoro \\ ${ }^{2}$ Assistant Professor, Department of Community Medicine, Isra University, Hyderabad \\ ${ }^{3,4}$ Senior Lecturer, Department of Community Health Sciences, Bahria University Medical \& Dental College, Karachi \\ ${ }^{5}$ Associate Professor, Department of Community Medicine, Shaheed Mohtarma Benazir Bhutto Medical University, \\ Sindh \\ ${ }^{6}$ Student, Final Year MBBS, Isra University, Hyderabad
}

\begin{abstract}
Background: With the advances in information and technology, internet addiction appears as a serious obsessive condition that has various negative consequences on human physical and mental wellbeing. The objective of the study was to determine the use of internet and its level of addiction among medical undergraduate students studying at Isra University, Hyderabad.

Methods: This cross-sectional study was carried out at the Isra University, Hyderabad between August and December 2019. Undergraduate Medical (MBBS) students of either gender were invited to participate in the study. Stratified sampling technique was applied for the selection of participants. A structured 5-point Likert scale questionnaire for the internet addiction test was adopted from Dr. Kimberly Young and used for the measurement of participant's internet addiction level.

Results: A total of 263 students were included in the study. Over half (54.37\%) of them were male while $51.71 \%$ were from the age group $21-22$ years. Internet addiction was found prevalent in $85.17 \%$ of participants. Of these, $54.37 \%$ were mild or minimal internet addicts while $10.27 \%$ were severely addicted. A statistically significant difference $(p<0.05)$ was observed between gender, age groups, year of study, and current residential status of participants.

Conclusion: Students between the age group (19-20) years, hostlers, in $2^{\text {nd }}$ year of study and males were mainly addicted to internet.

Keywords: Internet addiction, Medical Students, Technology

Authors' Contribution:

${ }^{1,2}$ Conception; Literature research;

manuscript design and drafting; ${ }^{3,4}$ Critical

analysis and manuscript review; ${ }^{5,6}$ Data

analysis; Manuscript Editing.

Correspondence:

Tariq Feroz Memon

Email: drtariqferoz@gmail.com

Article info:

Received: June 2, 2021

Accepted: December 3, 2021
\end{abstract}

Cite this article. Memon TF, Baloch GH, Khan MT, Zehravi F, Soomro H, Motlani J. Internet Use and Its Addiction Among Medical Students in Hyderabad, Pakistan. J Islamabad Med Dental Coll. 2021; 10(4): 228-233. Doi:10.35787/jimdc.v10i4.724

Funding Source: Nil

Conflict of Interest: Nil

\section{Introduction}

The world has remodeled over recent years within the field of technology. In this remolding, the internet is one of the conducive factors to the current milestone. (1) Globally, the number of internet users have surged exponentially by one thousand-fold in last one and half decade. The recent report on internet users also indicated that over half of the world's population (approximately 4 billion people) have internet access. While in 2017 alone, about quarter a billion new internet users 
were recorded. (1) Inflated consumer demand has initiated competition among electronic suppliers. As a result, there is a fall in the prices of gadgets like laptops, desktop computers, pads, and mobile phones. ${ }^{(2)}$ After these advancements, the use of the internet has risen sharply, not just for communication, but as a tool for seeking information and marketing. Furthermore, an increase in internet coverage, especially among developing countries and rural areas, has made the internet a source of entertainment. Subsequently. it is rapidly becoming a part of daily life. ${ }^{(3)}$ The use of the net has brought many benefits within the education field. The ample provision of e-books, dictionaries, and encyclopedias made the pursuit of information faster and accessible. Moreover, simulation videos, PowerPoint presentations, and online slides provide a more precise, clear, and elaborate view of the topic under study ${ }^{(4)}$ Despite the many benefits of the web mentioned above, various adverse consequences are also becoming apparent. The array of the consequences involves excess money spent on web subscriptions and wastage of time while surfing on the net. In addition, issues related to mental health are raising like depression, ruined relationships, and job loss. (5) Arguably, the most concerning manifestation of this are pathological internet addiction. Specifically, internet addiction can be defined as the use of internet devices for 7 hours or more per day, which predisposes one to dependence and mental health problems. ${ }^{(6)}$ Moreover, it leads to disturbance of sleep, pain in the neck, strained eyes, traffic accidents, etc. Worldwide, mental disorders because of internet addiction are a novel health concern. The pathological internet addiction presents with compulsive behavior, poor performance in academia, and neglect of social and occupational responsibilities. (7) Furthermore, excessive internet use results in craving social media like Facebook, Instagram, Twitter, Snapchat, and WhatsApp. In addition, various other activities cause web addiction. For example, online gaming, listening to music, watching films, online shopping, and gambling. ${ }^{(8)}$

Internet addiction can be diagnosed by asking eight diagnostic questions. The answer to these questions can ascertain a specific type of internet addiction. ${ }^{(9)}$ However, pathological form of web addiction is common in college and university students. In addition, several studies have found an association between internet addiction and anxiety. Likewise, the high prevalence of internet addiction among medical students has become a serious concern. $(6,10)$ Limited information is available regarding internet addiction among the students. No study has been conducted on internet addiction among undergraduate medical students in Hyderabad so far. This study will help to get an insight into this issue that can help policy makers in devising strategies for its prevention and control.

\section{Methodology}

This cross-sectional study was carried out at the Isra University, Hyderabad between August and December 2019. Stratified sampling technique was applied for the selection of participants. The sample size of 237 was calculated, using the formula for anticipated population proportion (Raosoft). The confidence level of $95 \%, 5 \%$ margin of error and $19 \%$ anticipated proportion were used in the formula (11)(12) A total of 263 participants were included by applying calculation for Design Effect; to reduce the possibility of non-responsiveness. All medical students from 1st to Final year MBBS, who gave consent to participate were included. Incentives such as medical textbooks and/or dictionaries were provided to the students.

The study was ethically approved by the ethical review board of Isra University, Hyderabad while written informed consent was also sought from all the participants.

Socio-demographic details of all students (age, gender, marital status, ethnicity, religion and year of study, etc.) were gleaned, followed by a structured questionnaire consisting of 5-point Likert scale 
questions adopted from Dr. Kimberly Young, as a tool for internet addiction test (IAT). ${ }^{(9,13)}$ The IAT is a valid inventory that is used to measure the severity of self-reported compulsive use of the internet. The scores of internet addiction were categorized according to the responses of total 20 items of IAT, the maximum score 100 was considered as the extreme usage/severe addiction. While the IAT scores less than 30 meant normal internet users, 3149 mild addiction, 50-79 represented moderate addiction and 80-100 showed severe addiction. The questionnaires were circulated to the study participants soon after their morning lectures.

SPSS-23 was used for both the descriptive and inferential statistical analysis of data. Qualitative data was presented as numbers and percentages. Quantitative variables were measured as mean and standard deviation and analyzed using student ttests or one-way ANOVA, based on the classification of data available.

\section{Results}

The age range of the respondents was from 19 to 24 years with the mean age of $21.26 \pm 3.44$ years. The majority of respondents were from 2nd-year MBBS while most of the respondents were day scholars (Table I).

\begin{tabular}{|l|l|}
\hline $\begin{array}{l}\text { Table I: Socio-demographic details of study } \\
\text { participants ( } \mathbf{n}=\mathbf{2 6 3})\end{array}$ & $\mathrm{n}(\%)$ \\
\hline Variables & $143(54.37)$ \\
\hline Gender & $120(45.63)$ \\
Male & \\
Female & $104(39.54)$ \\
\hline Age group & $136(51.71)$ \\
19-20 years & $23(8.74)$ \\
21-22 years & \\
23-24 years & $63(23.96)$ \\
\hline Year of study & $81(30.79)$ \\
1st year & $67(25.47)$ \\
2nd year & $31(11.78)$ \\
3rd year & $21(8.00)$ \\
4th year & \\
5th year & $79(30.03)$ \\
\hline Present residence & $184(69.97)$ \\
Hostler & \\
Day scholar &
\end{tabular}

Platform participant spend the most time on the internet

Online games

$23(8.74)$

Movies/videos

Social Media

Learning websites

$75(28.52)$

$152(57.80)$

$13(4.94)$

The majority of study participants $(n=224)$ scored between 31 and 100 in IAT and were found to be addicted to the internet (Figure 1).

\section{Internet addiction status}

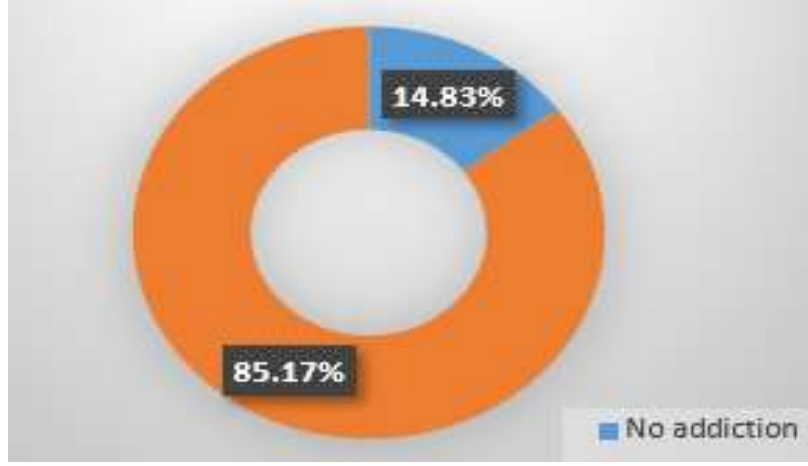

Figure 1: Status of internet addiction among medical students ( $\mathbf{n = 2 6 3 )}$

Out of the 224 addicted respondents, the majority of them were mild or minimal internet addicts (Table II).

\begin{tabular}{|c|c|c|}
\hline $\begin{array}{l}\text { Level of internet } \\
\text { addiction }\end{array}$ & Frequency (\%) & $\begin{array}{l}\text { Total Score } \\
\text { Range }\end{array}$ \\
\hline No addiction & 39 (14.83) & $<30$ \\
\hline Mild & $143(54.37)$ & $31-49$ \\
\hline Moderate & $54(20.53)$ & $50-79$ \\
\hline Severe & $27(10.27)$ & $80-100$ \\
\hline
\end{tabular}

Total 196 (74.5\%) participants strongly agreed that they often stay online longer than envisioned. While, 103 (39.16\%) respondents reported that they prefer the internet excitement to intimacy with their friends or family. Moreover, 105 (39.92\%) reported that they feel moody, nervous, or depressed after they become offline while this feeling disappears once they get back online. 
A statistically significant $(p<0.05)$ difference was found between the internet addiction scores of both genders. Male medical students that were found to be more addicted to the internet compared with their counterparts. The mean Internet addiction score was statistically highest among the age group 19-20 while lowest in the 23-24 years group.

Moreover, the mean internet addiction score was statistically highest in 2nd-year MBBS students while lowest in 5th-year medical students. Statistically significant difference was found in internet addiction level between hostlers and day scholars (Table III).

\begin{tabular}{|c|c|c|}
\hline \multicolumn{3}{|c|}{$\begin{array}{l}\text { Table III: Comparative analysis of mean internet } \\
\text { addiction scores with the demographic variables } \\
\text { ( } n=263)\end{array}$} \\
\hline Variable & \begin{tabular}{|l|} 
Internet \\
addiction score
\end{tabular} & \\
\hline & Mean ( \pm S.D) & $p$-value \\
\hline $\begin{array}{l}\text { Gender } \\
\text { Male } \\
\text { Female }\end{array}$ & $\begin{array}{l}52.77( \pm 14.67) \\
39.28( \pm 13.38)\end{array}$ & $0.001^{*}$ \\
\hline $\begin{array}{l}\text { Age group } \\
19-20 \\
21-22 \\
23-24\end{array}$ & $\begin{array}{l}57.30( \pm 14.42) \\
55.75( \pm 14.59) \\
48.52( \pm 14.40) \\
\end{array}$ & $0.033^{* *}$ \\
\hline $\begin{array}{l}\text { Year of study } \\
\text { 1st year } \\
\text { 2nd year } \\
\text { 3rd year } \\
\text { 4th year } \\
5 \text { th year }\end{array}$ & $\begin{array}{l}48.69( \pm 16.66) \\
52.39( \pm 16.03) \\
46.62( \pm 16.96) \\
45.19( \pm 16.52) \\
37.33( \pm 16.45)\end{array}$ & $0.007^{* *}$ \\
\hline $\begin{array}{l}\text { Present residence } \\
\text { Hostel } \\
\text { Day scholar }\end{array}$ & $\begin{array}{l}55.75( \pm 17.55) \\
48.82( \pm 17.89)\end{array}$ & $0.004^{*}$ \\
\hline
\end{tabular}

* Student's t-tests for gender and present residence

** ANOVA for age group and year of study

\section{Discussion}

Despite many advantages of internet usage, there are several adverse effects of its consumption which are evident. Adolescents especially students at all levels are more likely to become victim to internet addiction. Keeping in view these harmful effects, this study was planned to estimate the magnitude of internet addiction among medical students. The response rate in the study was $87.66 \%$ which was encouraging. This could be attributable to the students' incentives along with a thorough explanation of the study objectives. In the present study, $85.17 \%$ of participants are internet-addicted which is a large number. Ali et al reported $85 \%$ of their participants to be internet addicts. These findings are consistent with our study. ${ }^{(14)}$ This high number is quite alarming and this could be because medical students of Isra University have easy access to an internet facility and internet utilization by students is not regulated.

The results of the present study have revealed that only $14.83 \%$ of the respondents were regular internet users. As the number is very low, it indicates that internet addiction is rampant in the cohort of this study. Similar findings are also reported by Ali et al. and Ahmer et al. in their study ${ }^{(14,15)}$ while these findings are inconsistent with the findings of Nduanya et al who reported higher prevalence than our study. ${ }^{(16)}$

Our study discovered that $12.05 \%$ of respondents were severely addicted to the internet, many of the studies have reported the lower prevalence of severe internet addiction. ${ }^{(16-18)}$ Moreover, our study revealed that $63.84 \%$ of the respondents were mild or minimal and $24.11 \%$ were moderate internet addicts. These findings are comparable with studies by Ahmer et al., Chaudhari et al., and Haque et al. ${ }^{(1,}$ 15, 19)

Findings of the current study revealed that male medical students are more addicted to the internet compared with their counterparts. Our study findings are comparable to those reported by Javaeed et al., Imani et al, and Upadhayay et al. ${ }^{9,18,}$ ${ }^{20)}$ In addition, a systematic review by Shao et al also revealed that male students were more internet addicted than females students. ${ }^{(21)}$ These findings are in contrast with the findings of Ahmer et al where internet addiction among females was found to be more as compared to males. ${ }^{(15)}$ However, Ranganatha et al. haven't observed any variation in the mean internet addiction scores between both genders. $^{(22)}$ 
In this study, the internet addiction was found to be more prevalent among participants between age group 19-20 years, while this prevalence of internet addiction was declined in 23-24 years of age participants. This is possibly because with advancing age and maturity, medical students engage and focus more on other important responsibilities and trend of internet surfing decreases. These findings are consistent with the findings of earlier studies that reported a similar pattern. ${ }^{(1,14,15)}$

Lastly, it has been found that students residing in the hostel had the highest mean internet addiction score compared with day scholars. These findings are consistent with the findings of Qadir et al. ${ }^{(23)}$ This can also be explained as students residing in hostels, being alone, get bored and spend longer duration using the internet for change of mind.

The study has certain limitations. Foremost, it was conducted in only one public sector medical university. The information gathered from participants was only regarding the internet usage while data related to determinants of excess usage of the internet, time spent on the particular website or social media, the impact of internet addiction on mental health, etc. was not collected. Further studies are recommended in the future to address this issue more extensively.

\section{Conclusion}

Students between the age group (19-20) years, hostlers, in $2^{\text {nd }}$ year of study and males were mainly addicted to the internet. This rising burden of internet addiction predicts a probable increase in the number of severely internet addicts in the near future.

\section{References}

1. Haque $M$, Abubakar AR, Naina-Mohamed I, Saidin NB, Azhar NIK. Internet Addiction a Global Concern: A Cross-Sectional Appraisal amongst Imminent Medical Doctors of National Defence University of Malaysia. J Pharm Pract Community Med. 2019;5(4), 75-79. Doi:10.5530/jppcm.2019.4.19
2. Anandi BS, Gududur A. Technology addiction and associated health problems among medical students in Kalaburagi District. Nat J Comm Med. 2018;9(4):294-9. ISSN 22296816

3. Tsimtsiou Z, Haidich A-B, Spachos D, Kokkali S, Bamidis $P$, Dardavesis $T$, et al. Internet addiction in Greek medical students: an online survey. Academic Psychiatry. 2015;39(3):300-4. Doi:10.1007/s40596014-0273-x

4. Hashim R, Hameed S, Ayyub A, Ali S, Raza G. Internet use: Disruptive or enhancing towards learning? Views \& perceptions of undergraduate medical students. PAFMJ. 2016;66(1):157-61. ISSN : 2411-8842

5. Chupradit S, Leewattana A, Chupradit PW. The correlation analysis of Internet usage and depression among undergraduate university students in Thailand: cross-sectional study. J Adv Res Dyn Control Syst.2020;12:825-37.

Doi:10.5373/JARDCS/V12SP6/SP20201100

6. D'Souza L, Manish S, Raj S. Relationship between academic stress and internet addiction among college students. Int J Indian Psychol. 2018;6(2):1008. Doi: $10.25215 / 0602.010$

7. Ambad SNA, Kalimin KM, Yusof KMAAK. THE EFFECT OF INTERNET ADDICTION ON STUDENTS'EMOTIONAL AND ACADEMIC PERFORMANCE. E-Academia Journal. 2017;6(1). ISSN 2289-6589

8. Asrese $\mathrm{K}, \mathrm{Muche} \mathrm{H}$. Online activities as risk factors for Problematic internet use among students in Bahir Dar University, North West Ethiopia: A hierarchical regression model. PloS one. 2020;15(9):e0238804. Doi: 10.1371/journal.pone.0238804

9. Upadhayay N, Guragain S. Internet use and its addiction level in medical students. Adv Med Educ Pract. 2017;8:641-47. Doi: 10.2147/AMEP.S142199

10. Mostafa A, Hoque R, Chakraborty $R$, Haque $M$, Munna MS. Internet use and addiction: a crosssectional study to ascertain internet utilization level for academic \& non-academic purpose among medical and university students of Bangladesh. Konuralp Medical Journal. 2019;11(3):404-15. Doi: 10.18521/ktd.522996

11. Chathoth V, Kodavanji B, Arunkumar N, Pai SR. Internet behaviour pattern in undergraduate medical students in Mangalore. IJIRSET. 2013;2(6):2133-6. ISSN: 2319-8753

12. Raosoft I. Sample size calculator. 2004. Available from: ww raosoft com/samplesize. 2016.

13. Young K. Internet addiction test (IAT): Stoelting; 2016.

14. Ali R, Mohammed N, Aly H. Internet addiction among medical students of Sohag University, Egypt. J Egypt 
Public Health Assoc. 2017;92(2):86-95. Doi: 10.21608/EPX.2018.8946

15. Ahmer Z, Tanzil S. Internet addiction among social networking sites users: Emerging mental health concern among medical undergraduates of Karachi. PJMS. 2018;34(6):1473.

Doi: 10.12669/pjms.346.15809

16. Nduanya CU, Okwaraji FE, Onyebueke GC, Obiechina $\mathrm{KI}$. A cross sectional study on internet addiction, locus of control and psychological distress in a sample of Nigerian undergraduates. J Med Res. 2018;4(3):14650. ISSN: 2395-7565

17. Thakur A, Peepre K, Vaswani A, Gupta K, Verma A, Singh $D$, et al. Internet addiction, behavioral aspects and health-related problems associated with it: A cross-sectional study among engineering students of Jabalpur district. Int J Res Med Sci. 2018;6(1):253-8. Doi:10.18203/2320-6012.ijrms20175729

18. Javaeed A, Bint Zafar $M$, Iqbal $M$, Ghauri SK. Correlation between Internet addiction, depression, anxiety and stress among undergraduate medical students in Azad Kashmir. PJMS. 2019;35(2):506. Doi: 10.12669/pjms.35.2.169

19. Chaudhari B, Menon P, Saldanha D, Tewari A, Bhattacharya $L$. Internet addiction and its determinants among medical students. Ind Psychiatry J. 2015;24(2):158. Doi: 10.4103/09726748.181729

20. Imani A, Esmaeeli S, Golestani M, Ghoddoosi-Nejad D, Baghban Baghestan E, Arab-Zozani M. Relation between internet addiction and educational burnout among students in Faculty of Health Management and Medical Informatics of Tabriz University of Medical Sciences: A Cross-Sectional Study. Mod Care J. 2018;15(2). Doi: 10.5812/modernc.66027.

21. Shao Y-j, Zheng T, Wang Y-q, Liu L, Chen Y, Yao Y-s. Internet addiction detection rate among college students in the People's Republic of China: a metaanalysis. Child Adolesc Psychiatry Ment Health. 2018;12(1):1-10. Doi: 10.1186/s13034-018-0231-6

22. Ranganatha $S$, Usha $S$. Prevalence and pattern of internet addiction among medical students, Bengaluru. Int J Commun Med Pub Health. 2017;4(12):4680-4. Doi:10.18203/23946040.ijcmph20175350

23. Qadir S, Naeem A, Akhtar MN. INTERNET USE BEHAVIOR: EMERGING STUDENT MENTAL HEALTH PROBLEM. Gomal J Med Sci. 2018;16(2):39-42. Doi:10.46903/gjms/16.02.1920 